\title{
Increasing effects of chronic nutrient enrichment on plant diversity loss and ecosystem productivity over time
}

Eric W. Seabloom iD,${ }^{1,27}$ Peter B. Adler iD,${ }^{2}$ Juan Alberti, ${ }^{3}$ Lori Biederman, ${ }^{4}$ Yvonne M. Buckley, ${ }^{5}$ Marc W. Cadotte id ${ }^{6}$ Scott L. Collins iD ${ }^{7}$ Laura Dee, ${ }^{8}$ Philip A. Fay id,${ }^{9}$ Jennifer Firn id,${ }^{10}$ Nicole Hagenah, ${ }^{11}$ W. Stanley Harpole, ${ }^{12,13,14}$ Yann Hautier id ${ }^{15}$ Andy Hector, ${ }^{16}$ Sarah E. Hobbie, ${ }^{1}$ Forest Isbell id ${ }^{1}$ Johannes M. H. Knops, ${ }^{17}$ Kimberly J. Komatsu (iD,${ }^{18}$ Ramesh Laungani, ${ }^{19}$ Andrew MacDougall, ${ }^{20}$ Rebecca L. McCulley (iD, ${ }^{21}$ Joslin L. Moore id, 22 John W. Morgan, ${ }^{23}$ Timothy Ohlert, ${ }^{7}$ Suzanne M. Prober, ${ }^{24}$ Anita C. Risch id ${ }^{25}$ Martin Schuetz, ${ }^{25}$ Carly J. Stevens, ${ }^{26}$ and Elizabeth T. Borer ${ }^{1}$

\footnotetext{
${ }^{1}$ Department of Ecology, Evolution, and Behavior, University of Minnesota, St. Paul, Minnesota 55108 USA ${ }^{2}$ Department of Wildland Resources and the Ecology Center, Utah State University, 5230 Old Main, Logan, Utah 84322 USA ${ }^{3}$ Instituto de Investigaciones Marinas y Costeras (IIMyC), UNMdP-CONICET, FCEyN,CC1260, 7600, Mar del Plata, Argentina

${ }^{4}$ Ecology, Evolution, \& Organismal Biology, Iowa State University, 2200 Osborn Drive, Ames, Iowa 50011 USA ${ }^{5}$ Zoology, School of Natural Sciences, Trinity College Dublin, Dublin 2,Ireland

${ }^{6}$ Department of Biological Sciences, University of Toronto-Scarborough, 1265 Military Trail, Toronto, Ontario M1C 1 A4 Canada ${ }^{7}$ Department of Biology, University of New Mexico, Albuquerque, New Mexico 87131 USA

${ }^{8}$ Department of Ecology and Evolutionary Biology, University of Colorado Boulder, Boulder, Colorado 80302 USA

${ }^{9}$ USDA-ARS Grassland, Soil, and Water Laboratory, 808 East Blackland Road, Temple, Texas 76502 USA

${ }^{10}$ Science and Engineering Faculty, School of Earth, Environmental and Biological Sciences, Queensland University of Technology (QUT), Brisbane, Queensland 4001 Australia

${ }^{11}$ Department of Zoology and Entomology, Mammal Research Institute, University of Pretoria, Pretoria, South Africa

${ }^{12}$ Department of Physiological Diversity, Helmholtz Center for Environmental Research-UFZ, Permoserstrasse 15, Leipzig 04318 Germany

${ }^{13}$ German Centre for Integrative Biodiversity Research (iDiv), Deutscher Platz 5e, Leipzig 04103 Germany

${ }^{14}$ Martin Luther University Halle-Wittenberg, am Kirchtor 1, Halle (Saale) 06108 Germany

${ }^{15}$ Ecology and Biodiversity Group, Department of Biology, Utrecht University, Padualaan 8, Utrecht 3584 CH The Netherlands ${ }^{16}$ Department of Plant Sciences, University of Oxford, Oxford OX1 3RB UK

${ }^{17}$ Health \& Environmental Sciences Department, Xi' an Jiaotong-Liverpool University, Suzhou, China

${ }^{18}$ Smithsonian Environmental Research Center, 647 Contees Wharf Road, Edgewater, Maryland 21037 USA

${ }^{19}$ Department of Biology, Doane University, 1014 Boswell Avenue, Crete, Nebraska 68333 USA

${ }^{20}$ Department of Integrative Biology, University of Guelph, Guelph, Ontario N1G 2 W1 Canada

${ }^{21}$ Department of Plant \& Soil Sciences, University of Kentucky, Lexington, Kentucky 40536-0312 USA

${ }^{22}$ School of Biological Sciences, Monash University, Clayton, Victoria 3800 Australia

${ }^{23}$ Department of Ecology, Environment and Evolution, La Trobe University, Bundoora, Victoria 3086 Australia

${ }^{24}$ CSIRO Land and Water, Private Bag 5, Wembley, Western Australia 6913 Australia

${ }^{25}$ Swiss Federal Institute for Forest, Snow and Landscape Research WSL,Zuercherstrasse 111, Birmensdorf 8903 Switzerland

${ }^{26}$ Lancaster Environment Centre, Lancaster University, Lancaster LA1 4 YQ UK
}

Citation: Seabloom, E. W., P. B. Adler, J. Alberti, L. Biederman, Y. M. Buckley, M. W. Cadotte, S. L. Collins, L. Dee, P. A. Fay, J. Firn, N. Hagenah, W. S. Harpole, Y. Hautier, A. Hector, S. E. Hobbie, F. Isbell, J. M. H. Knops, K. J. Komatsu, R. Laungani, A. MacDougall, R. L. McCulley, J. L. Moore, J. W. Morgan, T. Ohlert, S. M. Prober, A. C. Risch, M. Schuetz, C. J. Stevens, and E. T. Borer. 2021. Increasing effects of chronic nutrient enrichment on plant diversity loss and ecosystem productivity over time. Ecology 102(2): e03218. 10.1002/ecy.3218

Abstract. Human activities are enriching many of Earth's ecosystems with biologically limiting mineral nutrients such as nitrogen $(\mathrm{N})$ and phosphorus $(\mathrm{P})$. In grasslands, this enrichment generally reduces plant diversity and increases productivity. The widely demonstrated positive effect of diversity on productivity suggests a potential negative feedback, whereby nutrient-induced declines in diversity reduce the initial gains in productivity arising from nutrient enrichment. In addition, plant productivity and diversity can be inhibited by accumulations of dead biomass, which may be altered by nutrient enrichment. Over longer time frames, nutrient addition may increase soil fertility by increasing soil organic matter and nutrient pools. We examined the effects of 5-11 yr of nutrient addition at 47 grasslands in 12 countries. Nutrient enrichment increased aboveground live biomass and reduced plant diversity at nearly all sites, and these effects became stronger over time. We did not find evidence that nutrient-induced losses of diversity reduced the positive effects of nutrients on biomass; however, nutrient effects on live biomass increased more slowly at sites where litter was also increasing, regardless of

Manuscript received 8 May 2020; revised 16 July 2020; accepted 24 August 2020. Corresponding Editor Name: Pamela Templer.

${ }^{27}$ E-mail: seabloom@umn.edu 
plant diversity. This work suggests that short-term experiments may underestimate the longterm nutrient enrichment effects on global grassland ecosystems.

Key words: biodiversity; community ecology; ecosystem ecology, grasslands; NutNet; nutrient network.

\section{INTRODUCTION}

Human activities have increased the input of limiting nutrients into many ecosystems through fossil fuel burning, agricultural fertilizer use, and other activities that create and distribute biologically available nutrients (Vitousek et al. 1997a, b, Steffen et al. 2015). This enrichment can alter ecosystem productivity, biogeochemistry, species richness, and species composition (Lawes and Gilbert 1880, Vitousek et al. 1997b, Elser et al. 2007, Hillebrand et al. 2007, Lewandowska et al. 2016, Simkin et al. 2016, Midolo et al. 2019). Because of the tight coupling between fluxes of inorganic and organic material and the effects of biodiversity on ecosystem processes (Hobbie 2008, Tilman et al. 2014, Hobbie 2015, Riggs et al. 2015), there is the potential for indirect effects or feedbacks that may increase or dampen the effects of global nutrient enrichment over time (Smith et al. 2009, Isbell et al. 2013a, Avolio et al. 2014, Smith et al. 2015).

Experimental work in grassland ecosystems illustrates the potential for indirect effects and feedbacks to alter the impacts of nutrient enrichment over time. In many types of grasslands (e.g., alpine tundra, Africa grassveld, montane meadows, mesic grasslands, prairies, desert grasslands, and old fields), addition of limiting mineral nutrients, such as $\mathrm{N}$ and $\mathrm{P}$, often rapidly leads to an increase in biomass production and a loss of plant diversity (Lawes and Gilbert 1880, Elser et al. 2007, Borer et al. 2014b, Fay et al. 2015, Gasarch and Seastedt 2015, Ward et al. 2017). Because of the negative effect of plant diversity loss on productivity (Reich et al. 2001, Tilman et al. 2014), nutrient-induced biodiversity losses may diminish the effect of nutrient addition on productivity over time (Isbell et al. 2013a). Nutrient enrichment also can alter decomposition rates and carbon cycling (Knorr et al. 2005, Hobbie 2008, Hobbie 2015, Riggs et al. 2015), which may change the accumulation of dead plant biomass. This accumulated dead biomass may limit plant productivity over time by creating a physical barrier or reducing light at ground level (Seastedt et al. 1991, Foster and Gross 1998, Coleman and Levine 2007, Clark and Tilman 2010, Seabloom 2010, Hobbie 2015).

Alternatively, positive feedbacks may enhance nutrient effects over time. For example, increased productivity can increase soil organic matter (Conant et al. 2001, Fornara and Tilman 2012), which in turn may increase water holding and cation exchange capacity, thereby reducing leaching and increasing nutrient retention (Hobbie 2008, Fornara and Tilman 2012, Isbell et al. $2013 b$, Hobbie 2015), potentially leading to further productivity increases. If nutrient effects on ecosystems develop slowly over time because of long-term feedbacks
(Smith et al. 2009, Isbell et al. 2013a, Avolio et al. 2014, Smith et al. 2015), our understanding of nutrient effects on ecosystems may be biased, because most experiments in ecology are relatively short term $(<5 \mathrm{yr}$; Elser et al. 2007, Silvertown et al. 2010, Pierik et al. 2011, Smith et al. 2015, Hughes et al. 2017).

Although fertilization experiments in grasslands have found that nutrient addition often initially increases aboveground plant biomass and decreases plant diversity (Elser et al. 2007, Borer et al. 2014b, Fay et al. 2015), a few longer-term (> 5 yr) experiments suggest that the positive effects of nutrients on aboveground live biomass will either remain constant or decline with time (Jenkinson et al. 1994, Isbell et al. 2013a, Avolio et al. 2014), whereas the effects on diversity or richness may continue to increase (Isbell et al. 2013a, Harpole et al. 2016; but see Pierik et al. 2011). However, drawing general inference about how nutrient effects might unfold over time is difficult, because of the conflicting evidence from experiments conducted at different locations using different treatments and sampling methodologies.

Here we address this knowledge gap by examining how increased nutrient supply $(\mathrm{N}, \mathrm{P}$, potassium, and micronutrients) affects aboveground live biomass, dead biomass (plant litter), and diversity over time using a 5-11-yr nutrient-addition experiment replicated at 47 grassland sites in 12 countries on six continents that are part of the Nutrient Network (NutNet) distributed experiment (Borer et al. 2014a, Borer et al. 2017). This experimental network provides novel insights, because each site uses the same treatments and sampling methodologies, in contrast to meta-analyses in which methodological and biological signals are often confounded (Elser et al. 2007, Gruner et al. 2008, Midolo et al. 2019). Furthermore, these nutrient additions are replicated across a wide range of grassland ecosystems including alpine tundra, montane meadows, mesic grasslands, prairies, desert grasslands, and old fields, thereby capturing important environmental gradients of elevation $(0-4,241 \mathrm{~m})$, latitude $\left(38^{\circ} \mathrm{S}\right.$ to $\left.69^{\circ} \mathrm{N}\right)$, mean annual precipitation (250-900 mm/yr), soil nutrient levels (e.g., 270-1,200 ppm N, 10-230 ppm P), species richness (3-26 species $/ \mathrm{m}^{2}$ ), and aboveground live biomass $\left(28-870 \mathrm{~g} / \mathrm{m}^{2}\right)$, our measure of net primary production. Analyses of short-term NutNet data have shown that nutrient addition generally decreases diversity and increases aboveground biomass (Borer et al. 2014b, Fay et al. 2015).

We focus on grasslands, because these systems have been used extensively to test the interactive effects of nutrient enrichment and biodiversity on ecosystem processes (Elser et al. 2007, Tilman et al. 2014), and because grasslands account for about a third of 
terrestrial productivity (Chapin et al. 2002), making them important regulators of the global carbon cycle and climate. From a conservation perspective, grasslands are among the most endangered of the terrestrial ecosystems because of extensive conversion to human-dominated land uses, biological invasions, and well-documented loss of diversity in response to nutrient enrichment (Hoekstra et al. 2005, Ramankutty et al. 2008, Seabloom et al. 2013). Grasslands are also logistically tractable, as the small stature of the plants allows for smaller plot sizes. In addition, a few plant families of similar structure dominate grasslands worldwide, which makes it easier to compare results across global grasslands.

In our analyses, we explicitly ask (1) if the strength of nutrient effects on plant biomass and diversity changes over time, (2) if nutrient-induced diversity loss reduces the positive effects of nutrient addition on plant biomass, and (3) whether the nutrient-induced accumulation of dead biomass reduces the positive effects of nutrient addition on plant biomass?

\section{Methods}

\section{Study system and experimental design}

This work was conducted within the Nutrient Network Distributed Experiment, a globally replicated nutrient and herbivore manipulation experiment (NutNet; www.nutnet.org) (Borer et al. 2014a, Borer et al. 2017). For this study, we used data from 47 sites that had been receiving nutrient addition for 5-11 yr (Appendix S1: Table S7). At each of these sites, we replicated an identical experiment that factorially combined three nutrient-addition treatments each at two levels (Control or Fertilized): Nitrogen Addition $\quad\left(+\mathrm{N} ; \quad 10 \mathrm{~g} \mathrm{~N} \cdot \mathrm{m}^{-2} \cdot \mathrm{yr}^{-1}\right.$ as timed-release urea), Phosphorus Addition $\left(+\mathrm{P} ; 10 \mathrm{~g} \mathrm{P} \cdot \mathrm{m}^{-2} \cdot \mathrm{yr}^{-1}\right.$ as triple-super phosphate), and Potassium and Micronutrient Addition $\left(+\mathrm{K} ; 10 \mathrm{~g} \mathrm{~K} \cdot \mathrm{m}^{-2} \cdot \mathrm{yr}^{-1}\right.$ as potassium sulfate and $100 \mathrm{~g} \cdot \mathrm{m}^{-2} \cdot \mathrm{yr}^{-1}$ of a micronutrient mix $(6 \% \mathrm{Ca}, 3 \% \mathrm{Mg}, 12 \% \mathrm{~S}, 0.1 \% \mathrm{~B}, 1 \% \mathrm{Cu}, 17 \% \mathrm{Fe}$, $2.5 \% \mathrm{Mn}, 0.05 \% \mathrm{Mo}$, and $1 \% \mathrm{Zn}) . \mathrm{N}, \mathrm{P}$, and $\mathrm{K}$ were applied annually, and the micronutrient mix was applied once at the start of the study to avoid toxicity of largely immobile micronutrients.

The $\mathrm{N}$ addition rate $\left(10 \mathrm{~g} \mathrm{~N} \bullet \mathrm{m}^{-2} \cdot \mathrm{yr}^{-1}\right)$ was chosen to overcome $\mathrm{N}$ limitation, and is higher than would be used if the goal were to mimic anthropogenic $\mathrm{N}$ deposition (Clark and Tilman 2008, Stevens et al. 2015). Ammonium nitrate was used in 2007 instead of urea at some sites, but there were no detectable differences between these $\mathrm{N}$ sources on plant biomass or diversity (Seabloom et al. 2015).

Each site was set up as a completely randomized blocked design typically with three replicates (ranged from 1 to 6 ). The experimental unit was a $5 \times 5 \mathrm{~m}$ plot.

\section{Data collection}

Starting in the year prior to fertilization, we annually sampled aboveground plant biomass and plant community composition. Biomass was sampled by clipping all aboveground biomass (live and dead) in two $0.1 \times 1 \mathrm{~m}$ strips, sorting current year's biomass (live biomass) from previous year's biomass (dead biomass), drying the biomass to a constant mass at $60{ }^{\circ} \mathrm{C}$, and weighing it to the nearest $0.01 \mathrm{~g}$. The locations of the biomass strips were moved each year to avoid effect of previous harvests on production estimates in subsequent years. We sampled plant community composition in a permanent $1 \times 1 \mathrm{~m}$ quadrat by visually estimating the areal cover of each species independently, such that the total summed cover may exceed $100 \%$ in multilayer communities.

Soil samples were collected in the year before fertilization started and every 3-5 yr thereafter. For this, soil from several 10-cm-deep cores was combined for each plot and air-dried to a constant mass. All soils were then shipped to a lab at the University of Minnesota (USA) for storage and processing prior to analyses. Total carbon (C) and $\mathrm{N}$ were measured at the UMN lab. Soils were shipped to Waypoint Analytical (Memphis, Tennessee, USA) to measure major nutrients ( $\mathrm{P}$ and $\mathrm{K}$ ), micronutrients (e.g., $\mathrm{Ca}$ and $\mathrm{Mg}$ ), soil $\mathrm{pH}$, organic matter, cation exchange capacity (CEC), and texture of the soil (percent sand, silt and clay; only measured in the Control Plots). Detailed soil methods are presented in Appendix S1.

\section{Diversity metrics}

We measured plant diversity as the Effective Number of Species based on the Probability of Interspecific Encounter $\left(E N S_{P I E}\right)$, as this measure provides a more scale-independent measure of potential biodiversity effects than richness and is more robust to the effect of rare species than species richness (Chase and Knight 2013). $E N S_{P I E}$ is equivalent to the Inverse Simpson's index of diversity. We calculated $E N S_{P I E}$ as $1 / \sum_{i=1}^{S} p_{i}^{2}$ where $S$ is the total number of species and $p_{i}$ is the proportion of the community cover represented by species $i$ (Chase and Knight 2013). Simpson's evenness $(E)$ is directly related to $E N S_{P I E}$ through the relationship $E=-$ $E N S_{P I E} / \mathrm{S}$ (Smith and Wilson 1996); thus we can factor diversity directly into its richness and evenness components through the relationship:

$$
E N S_{P I E}=S * E
$$

$E N S_{P I E}$ was positively correlated with richness $(r=0.74)$ but only weakly correlated with evenness $(r=0.16)$ across all samples in our data. Richness and evenness were negatively correlated $(r=-0.41)$. 


\section{Data analyses}

Ecosystem responses to nutrient enrichment may follow a variety of different trajectories over time (e.g., no change or accelerating, decelerating, or linear change) (Smith et al. 2009, Smith et al. 2015). To capture these different trajectories, we fit a flexible model that allowed for nutrient effects to increase or decrease in strength over time and for the shape of these curves to vary. Considering the case where nutrient effects are getting stronger over time, we might see a number of different curve shapes:

Case 1. Decelerating effects over time.-This would be the case where effects initially increase in strength, but this rate of change slows as the system starts equilibrating to a new level (e.g., Isbell et al. 2013a). In this case, a plot of effect size over time will be concave down.

Case 2. Accelerating effects over time.-In this case, we would see little response for a period of time and then a rapidly increasing effect size. This could occur in a buffered system, where a treatment needs to exceed a threshold before the system changes. In this case, a plot of effect size over time will be concave up.

Case 3. Linear effects over time.-We used a statistical model that allows all of these shapes. Specifically, our statistical model of biomass or diversity change over time was as follows:

$$
\log (y)=\beta_{0}+\beta_{1} N+\beta_{2} \log (t)+\beta_{3} \log (t) N
$$

where $\beta_{i}$ is the $i$ th regression coefficient, $N$ is a dummy variable that indicates whether a sample is from a control plot $(N=0)$ or a nutrient addition plot $(N=1)$, and $t$ is the duration of the experiment (years of treatment). For control plots $(N=0)$, our predictive equation in log space is

$$
\log (y)=\beta_{0}+\beta_{2} \log (t)
$$

and for nutrient addition plots, our predictive equation is

$$
\log (y)=\left(\beta_{0}+\beta_{1}\right)+\left(\beta_{2}+\beta_{3}\right) \log (t) .
$$

In the case where we were modeling plant biomass ( $y=\log$ (biomass), $\beta_{0}$ is the mean biomass $\left(\log \mathrm{g} / \mathrm{m}^{2}\right)$ in a control plot at time $=1, \beta_{1}$ is the marginal increase in biomass $\left(\log \mathrm{g} / \mathrm{m}^{2}\right)$ due to adding nutrients in year $1, \beta_{2}$ is the change in mean biomass (log g per log yr), and $\beta_{3}$ is the marginal effect of adding nutrients on the change in mean biomass (log g per log yr).

In backtransformed space, we get the following relationship:

$$
y=e^{\beta_{0}+\beta_{1} N} t^{\beta_{2}+\beta_{3} N} .
$$

For control plots $(N=0)$, our predictive equation is

$$
y=e^{\beta_{0}} t^{\beta_{2}} .
$$

In this case, if $\beta_{2}<1$ the rate of biomass change over time is slowing (Case 1), if $\beta_{2}>1$ the rate of biomass change over time is increasing (Case 2), and if $\beta_{2}=1$ there is a linear change in biomass over time (Case 3 ). The mean biomass $(\mathrm{g})$ in a control plot in year $1(t=1)$ is $e^{\beta}$.

For nutrient addition plots, our predictive equation is

$$
y=e^{\beta_{0}+\beta_{1}} t^{\beta_{2}+\beta_{3}} .
$$

In this case, if $\left(\beta_{2}+\beta_{3}\right)<1$ the rate of biomass change over time is slowing (Case 1$)$, if $\left(\beta_{2}+\beta_{3}\right)>1$ the rate of biomass change over time is increasing (Case 2), and if $\left.\beta_{2}+\beta_{3}\right)=1$ there is a linear change in biomass over time (Case 3). The mean biomass ( $\mathrm{g}$ ) in a fertilized plot in year $1(t=1)$ is $e\left(\beta_{0}+\beta_{1}\right)$.

To test whether the effects of nutrient addition increased over time, we used a mixed-effects model with $+\mathrm{N}$, $+\mathrm{P}$, and $+\mathrm{K} \mu$, and experimental duration. Experimental duration is the number of years the nutrient treatments had been applied; experimental duration was $\log _{10}$ transformed. We included experimental duration and site as random effects. Because of the large number of parameters, the model with effects of all eight nutrient treatments $(+\mathrm{N} \times+\mathrm{P} \times+\mathrm{K} \mu)$ and their interactions with experimental duration with random slope and intercepts for each site did not converge. For this reason, we estimated treatment differences among sites (random slopes and intercept) over time using only the Control and All Nutrient $(+\mathrm{N},+\mathrm{P}$, and $+\mathrm{K} \mu)$. Model specifications in $\mathrm{R}$ are included with each table of regression results (Tables $\mathrm{S} 1-\mathrm{S} 5$ ).

We tested for interactions between nutrient addition effects on live biomass, dead biomass, and diversity over time, to determine if nutrient effects became weaker over time at sites where nutrients lead to rapid declines in diversity or increases in dead biomass. To do this, we tested for correlations between the slopes of the nutrient effect on each of these metrics and experimental duration, as estimated by the nutrient effect by experimental duration interaction. For example, we tested if sites with increasing diversity losses over time would also eventually have weakening nutrient effects on live biomass over time. Similarly, if nutrient-induced increases in dead biomass reduced productivity, we would expect a negative correlation between the nutrient by experimental duration interaction for live and dead biomass, indicating that nutrient effects on dead biomass were increasing and nutrient effects on live biomass were decreasing over time. We tested this relationship using standardized major axis (SMA) estimation (Warton et al. 2012). SMA 
summarizes the relationship between two variables, as opposed to predicting the value of one variable (i.e., the dependent variable in regression) using a second variable (the independent variable in regression). We used the sma function in the smatr R library.

We also used regressions to examine whether nutrient effects on live biomass, dead biomass, and plant diversity increased or decreased over time. At the site level, we included a water-availability index (Mean Annual Precipitation/Potential Evapotranspiration), mean annual precipitation, mean annual temperature, mean diurnal temperature range, mean annual temperature range, and temperature in the wettest quarter. The plotlevel soil predictors were pretreatment soil $\mathrm{pH}$, total base cations (sum of $\mathrm{Ca}, \mathrm{Mg}$, and $\mathrm{K}$ ), $\%$ soil $\mathrm{N}$, and the soil $\mathrm{C}: \mathrm{N}$ ratio. Note that $\%$ soil $\mathrm{N}, \%$ soil organic matter, and $\%$ soil organic $\mathrm{C}$ are all highly correlated $(r>0.92$ for all comparisons), so we only included $\%$ soil $\mathrm{N}$ in the regression models. Similarly, cation exchange capacity and base cations are highly correlated $(r=0.93)$, so we only include base cations in the regression models. The plant community measures included were pretreatment live biomass, dead biomass, and plant diversity. Finally, we included the change in nutrient effect over time as described in the correlation analysis above. For example, we included the change in nutrient effect over time on dead biomass and plant diversity as explanatory variables of the change in nutrient effect over time on live biomass. In our regression of site-level characteristics that may predict the change in nutrient effects over time, many of our predictor variables covaried (e.g., pretreatment live biomass, soil $\mathrm{N}$, soil $\mathrm{C}: \mathrm{N}$, and water availability index). To account for the potential of multiple models that had similar explanatory power because of this correlation, we used a multimodel approach, as described in Grueber et al. (2011) using the dredge and model.avg functions in the MuMIn R library. We standardized the input variables using the arm R library. In the model averaging, we included all models within 4 corrected Akaike's information criterion $\left(\mathrm{AIC}_{\mathrm{c}}\right)$ units of the best model. We ran these models with and without soils data, as we were missing soils data at some sites.

All analyses were conducted in $\mathrm{R}$ (v. 3.4.1; R Core Team, 2018). Mixed effects models were fit using the lmer function in the lme4 $\mathrm{R}$ library.

\section{RESULTS}

Contrary to our expectations, we found increasing effects of nutrient addition on live biomass over time at most sites despite increasing losses of diversity (Figs. 1 and 2), and an overall significant interaction between treatment duration and fertilization (Appendix S1: Table S2). Although the nutrient effects grew stronger over time, the rate of change decelerated at most sites. Nutrient enrichment, especially the addition of $\mathrm{N}$, increased live biomass but did not have a consistent effect on dead biomass, and there was not an interaction between fertilization and treatment duration (Figs. 1 and 3; Appendix S1: Tables S1 and S2). The effects of nutrient enrichment on live biomass increased at most sites for up to $11 \mathrm{yr}$ (Fig. 1; Appendix S1: Tables S1 and $\mathrm{S} 2)$. In contrast to the consistent effects of nutrient addition on live biomass, nutrient effects on dead biomass were inconsistent, becoming stronger at some sites and weaker at others (Fig. 1; Appendix S1: Tables S1 and S2).

Nutrient addition caused increasingly strong reductions in plant diversity $\left(E N S_{P I E}\right)$ at nearly all sites (Figs. 2 and 3; Appendix S1: Tables S1 and S2), primarily because of the effects of $\mathrm{N}$ addition (Fig. 3, Appendix S1: Table S1). This loss in diversity was caused by increasing losses of richness at all sites (Figs. 2 and 3); nutrient effects on evenness did not show a consistent increase over time (Fig. 2).

The change in nutrient effects on diversity over time was not correlated with change in nutrient effects on live biomass over time (Fig. 4); however, there was a negative correlation between the trajectory of nutrient effects on live and dead biomass over time (Fig. 4). In addition to the negative effects of dead biomass on live biomass, we found evidence that nutrient effects on live biomass were stronger at more productive sites with higher pretreatment biomass (Appendix S1: Fig. S6, Tables S4 and S5). Similarly, we found that nutrient effects on diversity loss increased in strength faster at sites with higher initial diversity (Appendix S1: Fig. S6, Tables S4 and S5). Nutrient effects on dead biomass were weaker at sites with high levels of pretreatment dead biomass when we included soil chemistry in the models for 37 of 47 sites, but this effect was not significant for the full set of sites (Appendix S1: Fig. S6, Tables S4 and S5). Note that sites with domestic grazers had lower amounts of dead biomass in the control plots $(P=0.011)$.

There was no evidence that estimates of the change in nutrient effects over time were affected by among-site differences in experiment duration, which ranged from 5 to $11 \mathrm{yr}$ (Appendix S1: Tables S4 and S5). Furthermore, the change in nutrient effects over time was not dependent on a site's climate or soil chemistry (Appendix S1: Tables S4 and S5).

Nutrient addition increased soil nutrient pools, carbon, and organic matter. Specifically, $\mathrm{N}$ addition led to increased soil C and N (Appendix S1: Fig. S7, Table S6), and $\mathrm{P}$ addition increased soil $\mathrm{P}$, cation exchange capacity, and base cations (Appendix S1: Fig. S7, Table S6).

\section{Discussion}

Short- and long-term studies have identified different responses to chronic nutrient enrichment. Although an analysis of nutrient responses at 42 grassland sites in the NutNet experiment found increasing effects of fertilization on live biomass over the short term ( 3 yr; Fay et al. 2015), we expected, based on previous long-term fertilization experiments, that the positive effects of nutrients 

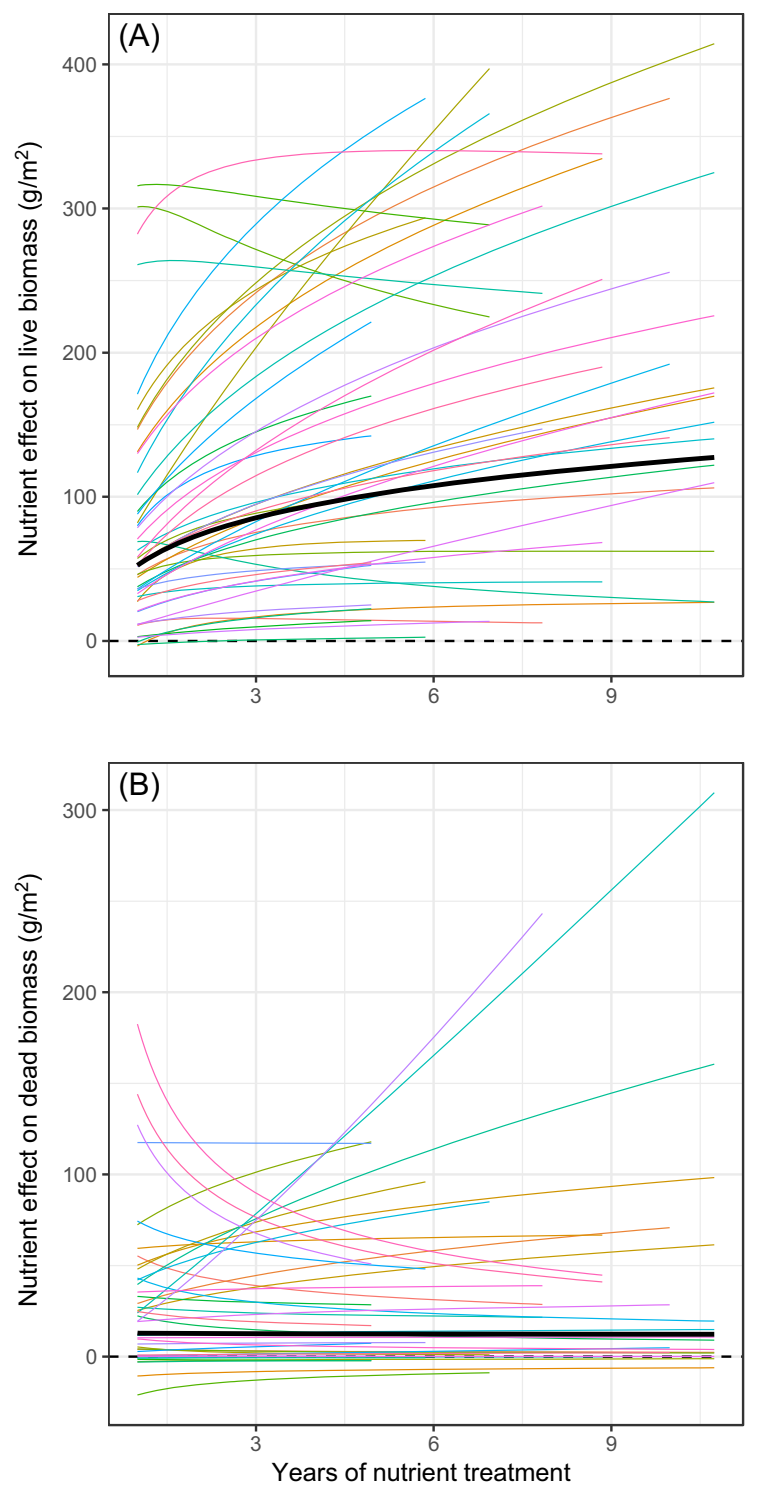

FIG. 1. Effect of nutrient enrichment on live (A) and dead (B) aboveground plant biomass in grassland ecosystems. Colored lines indicate individual sites, and the solid black line shows the mean response across sites. Models were fit using $\log _{10}$ (Treatment/Control) vs. $\log _{10}$ (Number of Years of Treatment), and backtransformed for plotting as the difference between Treatment (i.e., all nutrients added) and Control plots. Standard errors of all parameter estimates are presented in Appendix S1: Table S2, and site species models with raw data are presented in Appendix S1: Figs. S1 and S2.

on aboveground live biomass would either plateau and remain constant or decline with time (Jenkinson et al. 1994, Isbell et al. 2013a, Avolio et al. 2014). In contrast, we found that the effect of nutrient enrichment on live biomass continued to increase at nearly all sites for $11 \mathrm{yr}$ (Fig. 1; Appendix S1: Tables S1 and S2), despite increasing plant diversity losses and increasing dead biomass accumulation at some sites. Dead biomass accumulation was the strongest predictor of the nutrient effect trajectory over time, with increased biomass accumulation reducing the effects of nutrients on live biomass. We did not find any evidence that increasing diversity losses caused the nutrient effects on biomass to decline over time.

A possible mechanism explaining the increasingly strong fertilization effects on biomass is a concomitant increase in soil nutrient pools combined with a buildup of soil C and organic matter (Fornara and Tilman 2012, Crowther et al. 2019), which can lead to increased water holding capacity, cation exchange capacity, and nutrient retention (Fornara and Tilman 2012, Isbell et al. 2013b, Hobbie 2015). We found that $\mathrm{N}$ addition increased soil $\mathrm{C}$ and $\mathrm{N}$ (Appendix S1: Fig. S7, Table S4), and P addition increased soil $\mathrm{P}$, cation exchange capacity, and base cations, possibly because of the calcium $(\mathrm{Ca})$ in the $\mathrm{P}$ source (triple-super-phosphate; Appendix S1: Fig. S7, Table S6). These nutrient-induced alterations to soil chemistry may have caused the increase in productivity over time.

Although many studies have examined nutrient effects on plant productivity and biomass (Elser et al. 2007), there is little basis for a priori expectations of how nutrient effects on dead biomass accumulation would change over time, although we did expect a general coupling between live and dead biomass (Hobbie 2015, Grace et al. 2016). Dead biomass accumulation can directly reduce plant growth by acting as a physical barrier and reducing light to young plants (Foster and Gross 1998, Coleman and Levine 2007, Clark and Tilman 2010, Seabloom 2010). In the longer term, dead biomass can affect productivity through the influence of senesced plant material on nutrient cycling, either facilitating or delaying nutrient release to plants (Hobbie 2015). In contrast to the consistently positive effects of nutrients on live biomass, nutrient effects on the accumulation of dead biomass were inconsistent over time, increasing at some sites and decreasing at others (Fig. 1; Appendix S1: Tables S1 and S2).

Although we did not measure decomposition rates directly, our results suggest that nutrient addition may be increasing the rate of turnover of dead biomass, because fertilization increased biomass production and soil carbon, but it did not consistently increase total standing dead biomass. The effects of nutrients on decomposition are governed by complex feedbacks between primary productivity, plant tissue chemistry, and soil nutrient cycling (Knorr et al. 2005, Hobbie 2008, Hobbie 2015), and the effects can vary among different locations (Knorr et al. 2005, Hobbie 2008). Given the potential for increased nutrient supply rates to alter decomposition and ultimately carbon storage, developing a general understanding of nutrient supply on decomposition remains an important unresolved challenge in ecosystem ecology (Hobbie 2008).

Based on past work, we expected nutrients to reduce diversity over time (Isbell et al. 2013a, Harpole et al. 

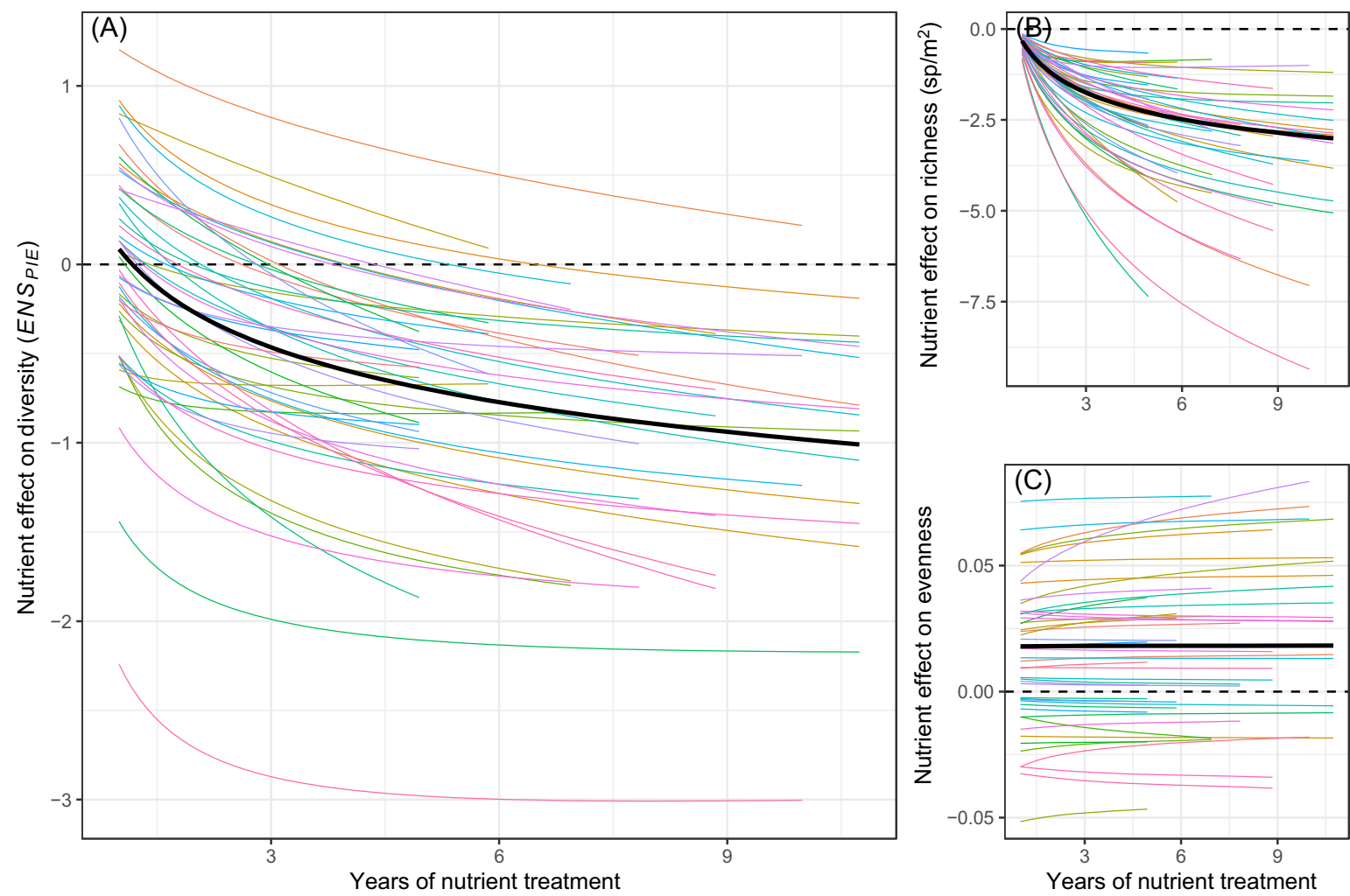

FIG. 2. Effects of nutrient enrichment on diversity $\left(E N S_{P I E}\right)(\mathrm{A})$, richness $\left(S\right.$, species $\left./ \mathrm{m}^{2}\right)(\mathrm{B})$, and evenness $\left(E N S_{P I E} S^{-1}\right)(\mathrm{C})$ in grassland ecosystems. Colored lines indicate individual sites, and the solid black line shows the mean response across sites. Models were fit using $\log _{10}$ (Treatment/Control) vs. $\log _{10}$ (Number of Years of Treatment), and backtransformed for plotting as the difference between Treatment (i.e., all nutrients added) and Control plots. Standard errors of all parameter estimates are presented in Appendix S1: Table S2, and site species models with raw data are presented in Appendix S1: Figs. S3, S4, and S5.

2016), and our results confirm this (Fig. 2; Appendix S1: Tables S1 and S2) and point to $\mathrm{N}$ as the main driver of increasing effects over time (Appendix S1: Table S1). Declines in diversity could arise either through reduced richness, because of increased extinction or reduced colonization rates, or reduced evenness, reflecting an increasingly skewed abundance distribution of species. We found that loss in diversity in response to nutrients was driven primarily by continuing richness loss at all sites (Fig. 2). In contrast to richness, nutrient addition did not have a consistent effect on evenness (Appendix S1: Tables S1 and S2), and nutrient effects on evenness did not show a consistent increase over time (Fig. 2), although evenness varied widely among sites and across years and nutrient addition did change evenness at individual sites (Appendix S1: Fig. S5).

Past work suggests that the positive effects of nutrient enrichment on live biomass declines when there is a concurrent loss in plant diversity (Isbell et al. 2013a) or increase in dead biomass. We tested for this relationship by examining the correlations between the change over time in the nutrient effects on live biomass, dead biomass, and plant diversity. We found no evidence of a negative feedback between fertilization-induced diversity loss and live biomass; live biomass continued to increase in response to nutrient addition for up to 11 yr. Furthermore, sites experiencing ongoing diversity loss did not have declining nutrient effects on live biomass over time (Fig. 4), as would be expected if the nutrient-induced diversity loss were counteracting nutrient effects on productivity (Isbell et al. 2013a). It is possible that the diversity loss may eventually start to counteract the positive effects of nutrients on plant biomass, as has been shown in an experiment that added nutrients for more than $25 \mathrm{yr}$ (Isbell et al. 2013a). However, the longest-running nutrient addition experiment has not shown large shifts after more than a century (Jenkinson et al. 1994). Thus, there is currently no consensus on how changes in biodiversity will influence nutrient effects on biomass production over multidecadal time periods.

Ultimately, standardized, long-term experiments replicated at sites representing a range of conditions are necessary to distinguish biological from methodological effects of nutrient addition studies (Borer et al. 2017). For example, Avolio et al. (2014) found that a decade of $\mathrm{N}$ and $\mathrm{P}$ addition did not alter the richness in a tallgrass prairie community, whereas Isbell et al. (2013a), using different methods, found that the effects of nutrient 

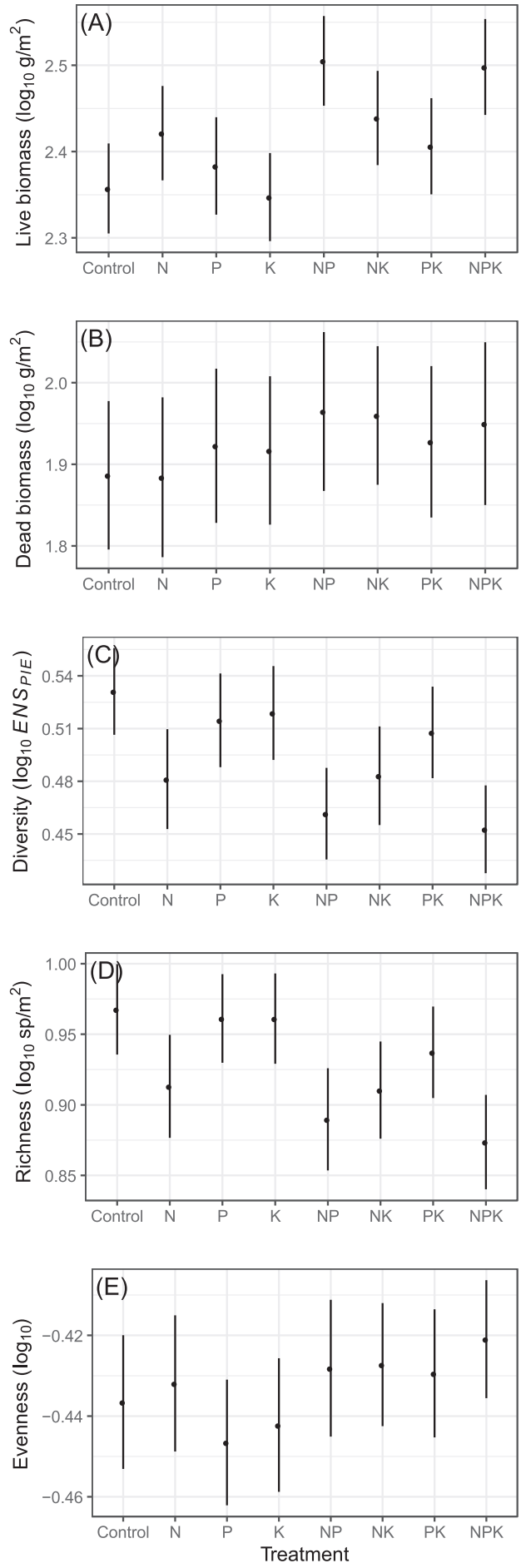

FIG. 3. Effects of nutrient addition treatments on live (A) and dead (B) aboveground plant biomass and diversity $\left(E N S_{P I E}\right)$ (C), richness $\left(S\right.$, species $\left./ \mathrm{m}^{2}\right)$ (D), and evenness $\left(E N S_{P I E} S^{-1}\right)(\mathrm{E})$ in grassland ecosystems. Error bars indicate 1 standard error (SE) among site means for each treatment. Parameter estimates and standard errors for all treatment effects are shown in Appendix S1: Table S1. addition on richness strengthened over time in a different tallgrass prairie. In contrast, our standardized experiment collocated with these previous studies showed a consistent response of increasing richness declines over time (konz.us and cdcr.us; Appendix S1: Figs. S1, S3, and S4), suggesting that methodological differences, such as nutrient addition rates or sampling protocols, do influence study results and conclusions (Isbell et al. 2013a, Avolio et al. 2014).

Our experiment was replicated across a wide range of conditions globally, underscoring the generality of the strengthening of nutrient effects over time. At
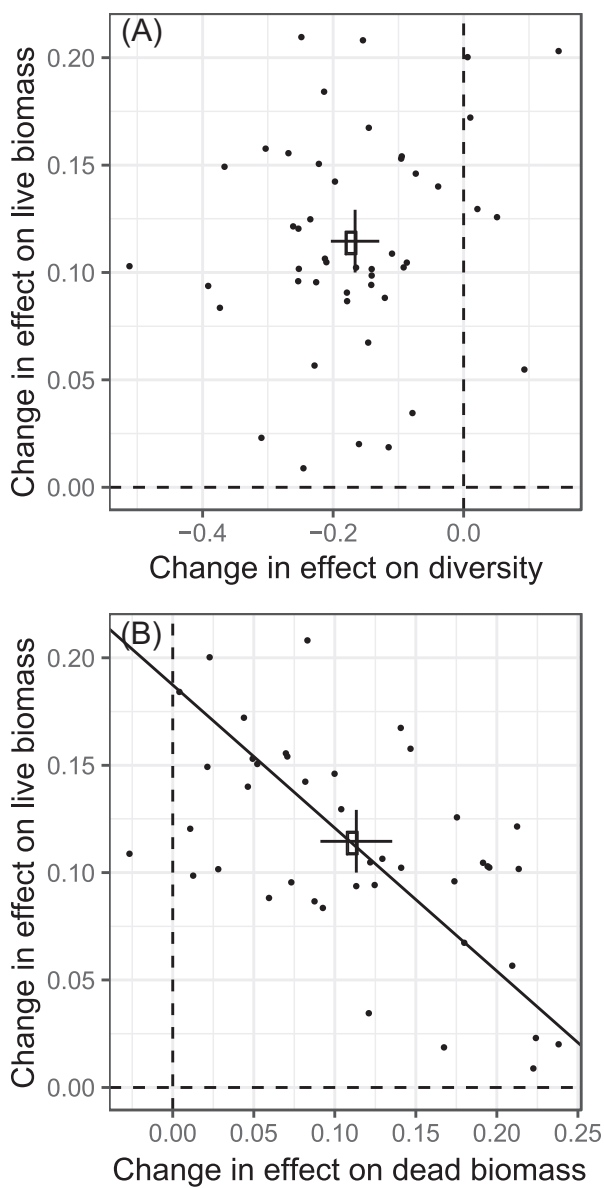

FIG. 4. Change over time of the effects of nutrient enrichment on live biomass (A, B), dead biomass (B), and diversity (A) at individual sites (slopes in Fig. 1). Values of zero (dashed lines) indicate effects that are constant over time, positive values indicate increasing effects over time, and negative values indicate decreasing effects over time. All slopes are from $\log _{10}$-transformed variables versus $\log _{10}$-transformed number of years of treatment. Diversity is measured as $E N S_{P I E}$. Correlations and significant tests are based on standardized major axis (SMA) estimation and are detailed in Appendix S1: Table S3. Large open circles represent the mean value across all sites with error bars representing two standard errors of the mean (SEM). 
nearly all sites, nutrient effects on live biomass and diversity became stronger over time. This suggests that short-term experiments $(<5 \mathrm{yr})$ will underestimate the effects of nutrient enrichment on ecosystems and communities. Experiments spanning multiple decades have shown that short-term experiments may generate biased estimates of long-term treatment effects (Reich et al. 2012, Isbell et al. 2013a, Komatsu et al. 2019), highlighting the value of long-term ecological data (Hughes et al. 2017).

In interpreting our results, it is important to note that the $\mathrm{N}$ addition rates $\left(10 \mathrm{~g} \mathrm{~N} \cdot \mathrm{m}^{-2} \cdot \mathrm{yr}^{-1}\right)$ we use were chosen to overcome $\mathrm{N}$ limitation, and are higher than would be used if the goal were to mimic anthropogenic $\mathrm{N}$ deposition (Clark and Tilman 2008, Stevens et al. 2015). Lower rates of $\mathrm{N}$ addition would likely lead to weaker effects, though still positive, effects on live biomass and richness, and could potentially inhibit decomposition rates (Knorr et al. 2005, Isbell et al. 2013a, Midolo et al. 2019).

Many experiments and models have demonstrated that nutrient addition in grassland ecosystems can induce plant diversity declines (Lawes and Gilbert 1880, Miller et al. 2005, Clark et al. 2007, Harpole and Tilman 2007, Hautier et al. 2009, Borer et al. 2014c, Harpole et al. 2016, Ward et al. 2017), and the few long-term experiments have shown that these effects can continue for decades (Lawes and Gilbert 1880, Jenkinson et al. 1994, Isbell et al. 2013a, Ward et al. 2017). Here we have shown that an increasing effect of nutrients on diversity loss over time is a general phenomenon in many grassland ecosystems. This result suggests that current understanding, which is largely based on short-term experiments ( $<5 \mathrm{yr}$; Elser et al. 2007), may be underestimating the consequences of nutrient enrichment for biodiversity loss. The mismatch between short experimental duration and the time for ecosystems to respond fully to nutrient enrichment is particularly problematic, given that human activities are continuing to increase the supplies of limiting nutrients into many of Earth's ecosystems (Vitousek et al. 1997a, Galloway et al. 2008, Steffen et al. 2015).

Human activities are concurrently altering a variety of interacting environmental factors that drive ecosystem processes and ultimately ecosystem services that are necessary for human well-being (Vitousek et al. 1997a, b, Steffen et al. 2015), and the ecosystem-level effects of many of these changes may not be fully evident for a decade or more (Reich et al. 2012, Isbell et al. 2013a). For this reason, long-term experiments are critical for predicting the effects of humans on ecological systems (Silvertown et al. 2010, Hughes et al. 2017). Nevertheless, long-term experiments in ecology remain relatively rare, and funding such experiments is increasingly difficult (Silvertown et al. 2010, Hughes et al. 2017). Human impacts on ecosystems also vary spatially, and ecologists have recently started replicating experiments at global scales (Borer et al. 2014a, Borer et al. 2017). Now that some distributed experiments have been in place for more than a decade, we can ask novel questions about the factors that determine the trajectory of ecosystem response to global change (Borer et al. 2017). Here we have shown a remarkably consistent increasing effect of nutrient addition on plant production and concomitant decline in diversity in a wide array of grassland ecosystems including deserts, prairies, and alpine tundra. However, these responses were not fully coupled; nutrientinduced declines in diversity did not reduce the effects of nutrients on live biomass. These results suggest that, because of their short duration, many experiments to date have likely underestimated the effects of human-driven eutrophication on biodiversity loss and ecosystem productivity.

\section{AcKNowledgments}

This work was generated using data from the Nutrient Network $^{2}$ experiment, funded at the site scale by individual researchers. Coordination and data management have been supported by funding to E. Borer and E. Seabloom from the National Science Foundation Research Coordination Network (NSF-DEB-1042132) and Long Term Ecological Research (NSF-DEB-1234162 and DEB-1831944 to Cedar Creek LTER) programs, and the University of Minnesota's Institute on the Environment (DG-0001-13). We also thank the Minnesota Supercomputer Institute for hosting project data and the Institute on the Environment for hosting Network meetings.

\section{Literature Cited}

Avolio, M. L., S. E. Koerner, K. J. La Pierre, K. R. Wilcox, G. W. T. Wilson, M. D. Smith, and S. L. Collins. 2014. Changes in plant community composition, not diversity, during a decade of nitrogen and phosphorus additions drive aboveground productivity in a tallgrass prairie. Journal of Ecology 102:1649-1660.

Borer, E. T., J. B. Grace, W. S. Harpole, A. S. MacDougall, and E. W. Seabloom. 2017. A decade of insights into grassland ecosystem responses to global environmental change. Nature Ecology \& Evolution 1:0118.

Borer, E. T., W. S. Harpole, P. B. Adler, E. M. Lind, J. L. Orrock, E. W. Seabloom, and M. D. Smith. 2014a. Finding generality in ecology: a model for globally distributed experiments. Methods in Ecology and Evolution 5:65.

Borer, E. T. et al. 2014b. Herbivores and nutrients control grassland plant diversity via light limitation. Nature 508:517.

Borer, E. T., E. W. Seabloom, C. E. Mitchell, and J. P. Cronin. 2014c. Multiple nutrients and herbivores interact to govern diversity, productivity, composition, and infection in a successional grassland. Oikos 123:214-224.

Chapin, F. S., H. A. Mooney, and P. A. Matson. 2002. Principles of terrestrial ecosystem ecology. Springer, New York, New York, USA.

Chase, J. M., and T. M. Knight. 2013. Scale-dependent effect sizes of ecological drivers on biodiversity: why standardised sampling is not enough. Ecology Letters 16:17-26.

${ }^{2}$ http://www.nutnet.org 
Clark, C. M., E. E. Cleland, S. L. Collins, J. E. Fargione, L. Gough, K. L. Gross, S. C. Pennings, K. N. Suding, and J. B. Grace. 2007. Environmental and plant community determinants of species loss following nitrogen enrichment. Ecology Letters 10:596-607.

Clark, C. M., and D. Tilman. 2008. Loss of plant species after chronic low-level nitrogen deposition to prairie grasslands Nature 451:712-715.

Clark, C. M., and D. Tilman. 2010. Recovery of plant diversity following $\mathrm{N}$ cessation: effects of recruitment, litter, and elevated $\mathrm{N}$ cycling. Ecology 91:3620-3630.

Coleman, H. M., and J. M. Levine. 2007. Mechanisms underlying the impacts of exotic annual grasses in a coastal California meadow. Biological Invasions 9:65-71.

Conant, R. T., K. Paustian, and E. T. Elliott. 2001. Grassland management and conversion into grassland: Effects on soil carbon. Ecological Applications 11:343-355.

Crowther, T. W. et al. 2019. Sensitivity of global soil carbon stocks to combined nutrient enrichment. Ecology Letters 22:936-945.

Elser, J. J., M. E. S. Bracken, E. E. Cleland, D. S. Gruner, W. S. Harpole, H. Hillebrand, J. T. Ngai, E. W. Seabloom, J. B. Shurin, and J. E. Smith. 2007. Global analysis of nitrogen and phosphorus limitation of primary producers in freshwater, marine and terrestrial ecosystems. Ecology Letters 10:1135-1142.

Fay, P. A. et al. 2015. Grassland productivity limited by multiple nutrients. Nature Plants 1:5.

Fornara, D. A., and D. Tilman. 2012. Soil carbon sequestration in prairie grasslands increased by chronic nitrogen addition Ecology 93:2030-2036.

Foster, B. L., and K. L. Gross. 1998. Species richness in a successional grassland: Effects of nitrogen enrichment and plant litter. Ecology 79:2593-2602.

Galloway, J. N., A. R. Townsend, J. W. Erisman, M. Bekunda Z. C. Cai, J. R. Freney, L. A. Martinelli, S. P. Seitzinger, and M. A. Sutton. 2008. Transformation of the nitrogen cycle: Recent trends, questions, and potential solutions. Science 320:889-892.

Gasarch, E. I., and T. R. Seastedt. 2015. Plant community response to nitrogen and phosphorus enrichment varies across an alpine tundra moisture gradient. Plant Ecology \& Diversity 8:739-749.

Grace, J. B. et al. 2016. Integrative modelling reveals mechanisms linking productivity and plant species richness. Nature 529:390-393.

Gruner, D. S. et al. 2008. A cross-system synthesis of consumer and nutrient resource control on producer biomass. Ecology Letters 11:740-755.

Harpole, W. S. et al. 2016. Addition of multiple limiting resources reduces grassland diversity. Nature 537:93-96.

Harpole, W. S., and D. Tilman. 2007. Grassland species loss resulting from reduced niche dimension. Nature 446:791-793.

Hautier, Y., P. A. Niklaus, and A. Hector. 2009. Competition for light causes plant biodiversity loss after eutrophication. Science 324:636-638

Hillebrand, H. et al. 2007. Consumer versus resource control of producer diversity depends on ecosystem type and producer community structure. Proceedings of the National Academy of Sciences of the United States of America 104:10904-10909.

Hobbie, S. E. 2008. Nitrogen effects on litter decomposition: a five-year experiment in eight temperate grassland and forest sites. Ecology 89:2633-2644.

Hobbie, S. E. 2015. Plant species effects on nutrient cycling: revisiting litter feedbacks. Trends in Ecology \& Evolution 30:357-363.
Hoekstra, J. M., T. M. Boucher, T. H. Ricketts, and C. Roberts. 2005. Confronting a biome crisis: global disparities of habitat loss and protection. Ecology Letters 8:23-29.

Hughes, B. B. et al. 2017. Long-term studies contribute disproportionately to ecology and policy. BioScience 67:271-281.

Isbell, F., P. B. Reich, D. Tilman, S. E. Hobbie, S. Polasky, and S. Binder. 2013a. Nutrient enrichment, biodiversity loss, and consequent declines in ecosystem productivity. Proceedings of the National Academy of Sciences of the United States of America 110:11911-11916.

Isbell, F., D. Tilman, S. Polasky, S. Binder, and P. Hawthorne. 2013b. Low biodiversity state persists two decades after cessation of nutrient enrichment. Ecology Letters $16: 454-460$.

Jenkinson, D. S., J. M. Potts, J. N. Perry, V. Barnett, K. Coleman, and A. E. Johnston. 1994. Trends in herbage yields over the last century on the Rothamsted Long-term Continuous Hay Experiment. Journal of Agricultural Science 122:365-374

Knorr, M., S. D. Frey, and P. S. Curtis. 2005. Nitrogen additions and litter decomposition: A meta-analysis. Ecology 86:3252-3257.

Komatsu, K. J. et al. 2019. Global change effects on plant communities are magnified by time and the number of global change factors imposed. Proceedings of the National Academy of Sciences of the United States of America 116:17867-17873

Lawes, J. B., and J. H. Gilbert. 1880. Agricultural, botanical, and chemical results of experiments on the mixed herbage of permanent meadow, conducted for more than twenty years in succession on the same lands. Part 1. Philosophical Transactions of the Royal Society B 171:289-416.

Lewandowska, A. M. et al. 2016. The influence of balanced and imbalanced resource supply on biodiversity-functioning relationship across ecosystems. Philosophical Transactions of the Royal Society B 371:20150283.

Midolo, G., R. Alkemade, A. M. Schipper, A. Benitez-Lopez, M. P. Perring, and W. De Vries. 2019. Impacts of nitrogen addition on plant species richness and abundance: A global meta-analysis. Global Ecology and Biogeography 28:398-413

Miller, T. E., J. H. Burns, P. Munguia, E. L. Walters, J. M. Kneitel, P. M. Richards, N. Mouquet, and H. L. Buckley. 2005. A critical review of twenty years' use of the resource-ratio theory. American Naturalist 165:439-448.

Pierik, M., J. van Ruijven, T. M. Bezemer, R. Geerts, and F. Berendse. 2011. Recovery of plant species richness during long-term fertilization of a species-rich grassland. Ecology 92:1393-1398.

R Core Team.2018. R: A language and environment for statistical computing. R Foundation for Statistical Computing, Vienna, Austria.

Ramankutty, N., A. T. Evan, C. Monfreda, and J. A. Foley. 2008. Farming the planet: 1. Geographic distribution of global agricultural lands in the year 2000. Global Biogeochemical Cycles 22:1-19.

Reich, P. B. et al. 2001. Plant diversity enhances ecosystem responses to elevated $\mathrm{CO}_{2}$ and nitrogen deposition. Nature 410:809-812.

Reich, P. B., D. Tilman, F. Isbell, K. Mueller, S. E. Hobbie, D. F. B. Flynn, and N. Eisenhauer. 2012. Impacts of biodiversity loss escalate through time as redundancy fades. Science 336:589-592.

Riggs, C. E., S. E. Hobbie, E. M. Bach, K. S. Hofmockel, and C. E. Kazanski. 2015. Nitrogen addition changes grassland soil organic matter decomposition. Biogeochemistry 125:203-219. 
Seabloom, E. W. 2010. Spatial and temporal variability in propagule limitation of California native grasses. Oikos 120:291-301.

Seabloom, E. W. et al. 2020. Effects of chronic nutrient enrichment on plant diversity and ecosystem productivity, 2008-2019 ver 1. Environmental Data Initiative.https://doi. org/10.6073/pasta/d78e6e48df246a03129c85a6c1da00d6.

Seabloom, E. W. et al. 2013. Predicting invasion in grassland ecosystems: is exotic dominance the real embarrassment of richness? Global Change Biology 19:3677-3687.

Seabloom, E. W. et al. 2015. Plant species' origin predicts dominance and response to nutrient enrichment and herbivores in global grasslands. Nature Communications 6:8.

Seastedt, T. R., J. M. Briggs, and D. J. Gibson. 1991. Controls of nitrogen limitation in tallgrass prairie. Oecologia 87:72-79.

Silvertown, J. et al. 2010. Environmental myopia: a diagnosis and a remedy. Trends in Ecology \& Evolution 25:556-561.

Simkin, S. M. et al. 2016. Conditional vulnerability of plant diversity to atmospheric nitrogen deposition across the United States. Proceedings of the National Academy of Sciences of the United States of America 113:4086-4091.

Smith, B., and J. B. Wilson. 1996. A consumer's guide to evenness indices. Oikos 76:70-82.

Smith, M. D., A. K. Knapp, and S. L. Collins. 2009. A framework for assessing ecosystem dynamics in response to chronic resource alterations induced by global change. Ecology 90:3279-3289.
Smith, M. D. et al. 2015. Global environmental change and the nature of aboveground net primary productivity responses: insights from long-term experiments. Oecologia 177:935-947.

Steffen, W. et al. 2015. Planetary boundaries: Guiding human development on a changing planet. Science 348:1217.

Stevens, C. J. et al. 2015. Anthropogenic nitrogen deposition predicts local grassland primary production worldwide. Ecology 96:1459-1465.

Tilman, D., F. Isbell, and J. M. Cowles. 2014. Biodiversity and ecosystem functioning. Pages 471-493 in D. J. Futuyma, editor. Annual review of ecology, evolution, and systematics. Volume 45. Annual Reviews, Palo Alto, California, USA.

Vitousek, P. M., J. D. Aber, R. W. Howarth, G. E. Likens, P. A. Matson, D. W. Schindler, W. H. Schlesinger, and D. G. Tilman. 1997a. Human alteration of the global nitrogen cycle: Sources and consequences. Ecological Applications 7:737-750.

Vitousek, P. M., H. A. Mooney, J. Lubchenco, and J. M. Melillo. 1997b. Human domination of Earth's ecosystems. Science 277:494-499.

Ward, D., K. Kirkman, and Z. Tsvuura. 2017. An African grassland responds similarly to long-term fertilization to the Park Grass experiment. PLoS One 12:e0177208.

Warton, D. I., R. A. Duursma, D. S. Falster, and S. Taskinen. 2012. smatr 3-an R package for estimation and inference about allometric lines. Methods in Ecology and Evolution $3: 257-259$.

SUPPORTING INFORMATION

Additional supporting information may be found in the online version of this article at http://onlinelibrary.wiley.com/doi/ 10.1002/ecy.3218/suppinfo

\section{Data Availability Statement}

Data are publicly available on the Environmental Data Initiative platform (Seabloom et al. 2020). https://doi.org/10.6073/pasta/ d78e6e48df246a03129c85a6c1da00d6 